\title{
A educação pública e o ensino de História da América Latina no Brasil e na Argentina
}

\author{
Public education and the teaching of History of Latin \\ America in Brazil and Argentina
}

\section{La educación pública y la enseñanza de Historia de América Latina en Brasil y Argentina}

\author{
Juliana Pirola da Conceição* \\ Ernesta Zamboni**
}

\begin{abstract}
Resumo: O artigo trata da educação pública e do ensino de História no Brasil e na Argentina a partir das legislações e diretrizes curriculares nacionais das últimas décadas, para identificar o espaço relegado ao ensino de História da América Latina ao longo de uma trajetória escolar. Os lineamentos teóricos e metodológicos que serviram de base para as análises comparativas estão relacionados à abordagem das Histórias Conectadas, trazendo à tona semelhanças e diferenças contextualizadas pelos laços que ligam cada história nacional à dos demais países da região. No campo do currículo, considerou-se o currículo como prescrição, que sustenta místicas importantes sobre Estado, escolarização e sociedade. Ao final, pode-se concluir que, embora a temática tenha ganhado espaço em documentos mais atuais, a seleção e a organização dos conteúdos indicados para normatizar a educação nacional não permitem a identificação de interesses comuns, que poderiam atuar na construção de perspectivas coletivas de futuro para o continente.
\end{abstract} Palavras-chave: Currículo. Ensino de História. América Latina.

Abstract: This article deals with public education and the teaching of history in Brazil
and Argentina from the national legislations and curriculums from the last decades to
identify the space dedicated to the teaching of Latin American history over the school
years. The theoretical and methodological guidelines that served as the bases for the
comparative analyses are related to the approach of Connected Stories, bringing out the
similarities and differences contextualized by the ties that bind each national history to
the other countries of a region. In the specific case of the teaching of Latin American
history, such connections refer to the formative processes of today and the resources
that are used. In the field of curriculum, the curriculum asprescription was considered, whi-
ch supports important mystiques about state, schooling and society. At the end, it can

\footnotetext{
* Doutoranda do Programa de Pós-Graduação em Educação da Universidade Estadual de Campinas. E-mail: <jupirola@yahoo.com.br>

** Professora aposentada da Universidade Estadual de Campinas. E-mail: <ernesta.zamboni@terra.com.br>
} 
be concluded that, although the issue has gained space in most current documents, the selection and organization of content suitable for regulating national education does not allow an identification of common interests, which could act in building collective perspectives for the future of the continent.

Keywords: Curriculum. History Teaching. Latin America.

Resumen: Este artículo se ocupa de la educación pública y la enseñanza de Historia en Brasil y Argentina a partir de las legislaciones nacionales y los planes de estudios de las últimas décadas para identificar el espacio dedicado a la enseñanza de la Historia de América Latina durante los años escolares. Los lineamientos teóricos y metodológicos que sirvieron como base para los análisis comparativos se relacionan con el enfoque de las Historias Conectadas, y evidencian las similitudes y diferencias contextualizadas por los lazos que unen cada historia nacional a de los demás países de la región. En el caso específico de la enseñanza de la Historia de América Latina, plan de estudios es visto como prescripción, sustentando importantes místicas sobre el Estado, la escolarización y la sociedad. Al final, se puede concluir que, aunque el tema ha ganado espacio en la mayoría de los documentos actuales, la selección y organización de contenidos adecuados para la regulación de la educación nacional no permite la identificación de intereses comunes, que podría actuar en la construcción de perspectivas colectivas para la futuro del continente.

Palabras clave: Plan de estudios. Enseñanza de Historia. América Latina.

\section{Introdução}

A educação e o ensino de História no Brasil e na Argentina serão discutidos neste artigo a partir da análise de documentos oficiais das últimas décadas para identificar o espaço relegado ao ensino de História da América Latina ${ }^{1}$ em documentos oficiais ao longo de uma trajetória escolar.

O artigo está organizado em torno de três pontos principais: na primeira parte, intitulada "Histórias conectadas", serão expostos os lineamentos teóricos e metodológicos que serviram de base para as análises comparativas realizadas ao longo do artigo, trazendo à tona as semelhanças e diferenças contextualizadas pelos laços que ligam cada história nacional à dos demais países da região.

\footnotetext{
${ }^{1}$ Entende-se aqui que a América Latina é uma construção cultural, histórica, política e também geográfica. Comprimida entre o Rio Grande, ao norte, e a Patagônia, ao sul, ninguém duvida de que seja integrada pela América do Sul, pela América Central e pelo México, onde se fala não só espanhol e português, mas também idiomas nativos, além do inglês, do francês e do holandês (SADER et al., 2006). Há quem considere que as ilhas caribenhas de língua inglesa, por exemplo, não fazem parte da América Latina. Ao longo deste texto, entretanto, quando se menciona América Latina, subentende-se que está em pauta a totalidade do continente, incluindo o Caribe. Questões referentes à denominação e à delimitação do território latino-americano, assim como os elementos históricos e culturais configuradores de seu passado e das representações que se constroem sobre ele, são discutidas pelas autoras em Conceição e Zamboni, 2012.
} 
Na segunda parte, intitulada "A educação pública e o ensino de História da América Latina", será realizada uma breve apresentação dos sistemas educativos dos dois países a partir das reformas da década de 1990, para colocar em contexto o atual modelo de funcionamento do sistema educativo dos dois países, identificando os níveis e modalidades de ensino, o perfil dos docentes e os espaços curriculares para o ensino de História da América Latina.

$\mathrm{Na}$ terceira parte, intitulada "A história da América Latina nas diretrizes curriculares nacionais", as diretrizes curriculares nacionais de ambos os países serão analisadas a partir da sugestão de conteúdos históricos relacionados à América Latina, de modo a refletir sobre a contribuição da escolarização na construção de memórias e identidades orientadas à diversidade cultural que nos habita.

A proposta partiu do desafio de realização de uma pesquisa comparada ${ }^{2}$, ainda em andamento, sobre o papel do ensino de História na orientação de atitudes de jovens brasileiros e argentinos face à situação presente da América Latina, o que colocou em evidência a necessidade de conhecer e entender o funcionamento do sistema educacional dos dois países de modo comparado, não só no plano teórico mas também na prática.

Sabe-se que a instituição escolar estruturou, tradicionalmente, o ensino de História a partir da matriz nacionalista do século XIX, cujo objetivo era formar "brasileiros", "argentinos" ou "chilenos" para a nova sociedade nacional que estava forjando os Estados modernos. Mas, apesar de todas as mudanças que a disciplina sofreu ao longo dos séculos, o ensino de História segue refletindo as disputas nacionais em detrimento da valorização das similitudes de nosso processo histórico (CONCEIÇÃO, 2010; DIAS, 2011). Seja pelo desconhecimento dos países entre si, pela predominância de perspectivas europeias ou pela valorização das identidades nacionais, tornamo-nos "o outro" de nossa própria história.

Nessa perspectiva, investigar a contribuição do ensino de conhecimentos históricos relacionados à América Latina nas diretrizes curriculares nacionais de modo comparado é uma forma de autoconhecimento e de conhecimento mútuo, de divulgar pesquisas dos países envolvidos e de promover cooperação regional. Tais investigações contribuem para a construção do "código disciplinar" (CUESTA FERNANDEZ, 1997) da História da América Latina, tendo como referência a construção de identidades no continente na relação com os modos de educar de cada sociedade.

\footnotetext{
${ }^{2}$ A pesquisa está em andamento junto ao Programa de Doutorado em Educação da UNICAMP, com financiamento da FAPESP, e integra um projeto interinstitucional intitulado "PEABIRÚ: Ensino de História e Cultura Contemporânea", sob a coordenação da Professora Doutora Ernesta Zamboni (UNICAMP), envolvendo pesquisadores de cinco universidades brasileiras e uma argentina - UNICAMP, UFSC, UFJF, UFU, UEL e FLACSO/Argentina. O projeto teve início em 2009 e já está em sua segunda fase. Desde então, tem-se propiciado o intercâmbio entre os pesquisadores do projeto para o aprofundamento dos resultados das pesquisas realizadas.
} 
Uma discussão aprofundada sobre o conceito de identidade não caberia nos limites deste artigo. No entanto, é necessário explicitar a maneira como o empregamos, já que muitas vezes é utilizado com diferentes enfoques, abordagens e significações, seja na História, na Sociologia ou na Psicologia, que, longe de se oporem, se complementam no entendimento das interações entre o ser humano e a sociedade. Neste artigo, a "identidade" é entendida associada à construção de uma consciência histórica que surge do terreno das memórias, constitutiva de pertencimentos (nós) e alteridades (outros), resultante da dupla constatação de semelhanças e diferenças entre si mesmo, os outros e os grupos com os quais interagimos (LEITE, 2004).

As identidades são construídas no processo histórico das interações sociais, graças às quais construímos e geramos conhecimentos sobre nós mesmo e sobre os outros, como um sentimento de pertencimento a um mundo em transformação, atribuindo sentido a uma história comum e fazendo que o "nós" ou o "eu" transcenda além da expectativa de vida individual (ZAMBONI, 2003). Nesse processo, é preciso considerar que os conhecimentos que se pode construir em relação aos indivíduos e aos grupos mantêm certa distância dos sujeitos aos quais se referem. Não tratam efetivamente do que eles são, mas das ideias que construímos sobre eles, "algo" que se estabelece entre o sujeito que conhece e o objeto conhecido. São, portanto, representaçoes, no sentido estrito do termo, porque permitem evocar ideias sempre inapreensíveis em sua globalidade (DESCHAMPS; MOLINER, 2009, p. 76).

Sendo sociais, identidades são inevitavelmente históricas, submetidas à passagem do tempo e a transformações. Podemos, portanto, dizer que a memória é um elemento constituinte do sentimento de identidade, tanto individual como coletiva, na medida em que ela é também um fator extremamente importante do sentimento de continuidade e de coerência de uma pessoa ou de um grupo. Desta forma, as pessoas que vivenciaram o mesmo acontecimento deveriam sentir-se pertencentes ao mesmo grupo de destino, à mesma memória (POLLAK, 1992, p. 204).

No caso latino-americano, a questão das identidades tem sido abordada de maneira recorrente desde o processo de independência nas colônias ibéricas, quando a proposta de unidade da América hispânica, de Simón Bolívar, tornou-se referência simbólica para a concepção de uma América unida em torno de elementos identitários comuns (REICHEL, 2007). A expressão "América latina"3 teria sido cunhada por intelectuais hispano-americanos na França, a partir da década de 1850, como antítese da "América saxônica", num desejo de construir um "nós" europeu que permitisse a saída do "atraso" e o ingresso na "civilização".

\footnotetext{
${ }^{3}$ Para maiores reflexões sobre a gênese do termo e da ideia de "América Latina" confira: Ardao (1980), Rojas Mix (1991), Quijada (1998), Bruit (2000), Farret e Pinto (2011), Mignolo (2005), Conceição e Zamboni (2012).
} 
Ao longo dos processos de luta por independência, a autoafirmação de "americano" passou a corresponder a uma necessidade de se diferenciar também do "outro" europeu, pois assim se estabeleceria uma defesa contra possíveis ataques das antigas metrópoles. Em ambos os casos, tratava-se de buscar referências para lidar com as diferenças dentro e fora do próprio continente entre uma população "branca" de ascendência europeia.

Mais recentemente, na segunda metade do século XX, o debate foi retomado a partir dos novos movimentos revolucionários e dos novos imperativos econômicos internacionais, após a Segunda Guerra Mundial. O termo se estabeleceu definitivamente em 1948 com a fundação da CEPAL (Comissão Econômica para América Latina), como organismo das Nações Unidas. Entretanto, ele se difundiu intimamente associado ao conceito de "subdesenvolvimento", que aparece na década de 1950 e se perpetua até a atualidade (DIAS, 2011).

O fato é que o nome "América Latina" tornou-se tão popular nos últimos sessenta anos, tão expressivo, que já não serve só para designar o difícil século XIX ou um conjunto de países subdesenvolvidos, mas também para identificar certa comunidade de heranças e desafios comuns aos países que compõem o continente. Dessa forma, a opção pelo uso do termo "América Latina" neste trabalho, em referência a um território que pouco tem de "latino" - haja vista sua diversidade cultural, histórica e política - e que requer para si a construção de identidades próprias, é uma opção didática, não política ${ }^{4}$.

Como as representações identitárias só se tornam tangíveis para um grupo na medida em que seus membros acreditam em sua existência e partilham suas significações, este artigo propõe investigar em que medida os processos de enquadramento da memória (POLLAK, 1989) nos documentos oficiais e nas diretrizes curriculares do Brasil e da Argentina têm contribuído para o entendimento de que, apesar das particularidades da história de cada país, de cada região, de cada grupo social, a América Latina partilha uma história comum, que é diferente da dos demais continentes/nações 5 .

\footnotetext{
${ }^{4}$ Outros termos seriam mais apropriados para nomear nossa identidade, mas mudar o nome obviamente não significa mudar o objeto, nem o sentido do objeto, porque isso depende da autoridade de quem nomeia, de quem designa (BOURDIEU, 1989, p. 130) e com que finalidade, consciente ou não, dá nome aos lugares. Não se trata, portanto, de criar um novo termo guarda-chuva ou de criar uma identidade que suprima diferenças, em nome de uma essência integradora. A unidade que devemos buscar é a unidade de trajetórias e projetos de futuro (CONCEIÇÃO; ZAMBONI, 2012).
}

${ }^{5}$ Alguns autores (SADER, 2006; CARDOSO, 2006) apontam pelo menos três elementos compartilhados historicamente, ainda que com "variações nacionais" significativas: a conquista ibérica, a larga duração de regimes de trabalho coercitivo impostos a amplos contingentes de nativos e a adoção "precoce" das instituições políticas e jurídicas do liberalismo após os movimentos de independência. Na história mais recente, afirmase que outros quatro elementos se agregam: o influxo de amplos contingentes de imigrantes europeus, entre o final do século XIX e o início do XX, desencadeando uma nova rodada de integração e miscigenação social e étnica, que resultou em sociedades bastante heterogêneas e com graus de mestiçagem e mobilidade 
O projeto que defendemos é a eliminação do isolamento cultural entre as nações latino-americanas via ensino de História. Acreditamos que a valorização das similitudes de nosso processo histórico nos currículos oficiais e nas práticas didáticas cotidianas pode tornar possível a identificação de interesses comuns que poderão atuar na orientação da vida prática e na construção de perspectivas coletivas de futuro para o continente.

\section{Histórias conectadas}

A recusa do primado da homogeneidade dos processos educativos latino-americanos e, ao mesmo tempo, a suspeita em relação à originalidade de cada processo têm recolocado a necessidade de se pensar comparativamente o fenômeno da escolarização em diferentes espaços na América Latina (VIDAL, 2001). $\mathrm{Na}$ medida em que a história de cada país corre paralelamente às demais, atravessando processos sincrônicos bastante semelhantes - descentralização administrativa e financeira dos sistemas educativos, elaboração de diretrizes curriculares orientadas para a formação de competências, precarização dos vínculos e das condições de trabalho dos professores etc. -, não há como escapar às comparações.

Em cada país, esses processos são fruto de trajetórias históricas particulares, mas ninguém duvida que eles estejam "conectados" por laços que unem cada história nacional à dos demais países da região, aproximando uns dos outros. Dessa forma, considerar os fenômenos educativos inseridos em seus contextos históricos diversos, dentro de sua própria dinâmica e especificidade, não exclui a atribuição de sentido a uma história comum.

A expressão "histórias conectadas" foi inicialmente proposta pelo historiador indiano Sanjay Subrahmanyam (1997), e tem sido defendida por pesquisadores renomados, como Serge Gruzinski (2003), Maria Ligia Coelho Prado (2005) e Diana Gonçalves Vidal (2001, 2009), para tratar de fenômenos transnacionais no contexto latino-americano, como uma abordagem promissora para se evitar a projeção de um ponto de vista nacional sobre o outro.

$\mathrm{Na}$ concepção de Gruzinski, o conceito de Subrahmanyam abre possibilidades para se pensar em uma história global e multifacetada, com pontos de convergência que o pesquisador deve perceber para poder conectar.

social significativos quando comparados a outros continentes; a ocorrência de aceleradas migrações do campo para a cidade, especialmente a partir dos anos 1930, e de uma industrialização comandada pelo Estado nacional mediante a utilização de políticas de estímulo e proteção do mercado interno; o aumento das tensões sociais e políticas derivadas da entrada de novas massas urbanas no terreno da competição eleitoral e das reivindicações corporativas e da cidadania, levando à ruptura da ordem democrática e a uma sucessão de regimes autoritários em quase todos os países da região entre as décadas de 1970 e 1980; o colapso do "modelo de desenvolvimento", fruto de seu esgotamento e das transformações produtivas e tecnológicas acarretadas pela "globalização" e pela onda pró-democracia que varreu o continente a partir do início dos anos 1980 (CONCEIÇÃO; ZAMBONI, 2012). 
Parece-me que a tarefa do historiador pode ser a de exumar as ligações históricas ou, antes, para ser mais exato, a de explorar as connected histories se adotamos a expressão proposta pelo historiador do império português Sanjay Subrahmanyam. O que implica que as histórias só podem ser múltiplas - em vez de falar de uma História única e unificada com "h" maiúsculo. Essa perspectiva permite também a observação de que estas histórias estão ligadas e que se comunicam entre elas. Diante de realidades que convém estudar sob diversos aspectos, o historiador tem de converter-se numa espécie de eletricista encarregado de restabelecer as conexões internacionais e intercontinentais que as historiografias nacionais e as histórias culturais desligaram ou esconderam, entaipando as suas respectivas fronteiras. (GRUZINZKI, 2003, p. 323).

O conceito de "conexão" aqui empregado rompe com o princípio da unidimensionalidade dos fenômenos históricos, considerados exclusivamente em si mesmos e sem pontos externos de referência. Dessa forma, os fenômenos não são apenas considerados um ao outro, mas também um por meio do outro, em termos de relações, de interações, de movimento.

Estabelecer parâmetros para realizar comparações sobre temas educacionais em face às conexões históricas entre Brasil e Argentina impõe desafios e demanda cautela. O próprio processo de conhecimento do outro e de si próprio, nesta troca entre realidades culturais diversas, implica um confronto que vai além do mero conhecimento do outro (FRANCO, 2000, p. 198). O que propomos neste trabalho é que a comparabilidade, trazendo à tona as semelhanças e diferenças contextualizadas em suas particularidades históricas, promova a identificação de pontos de contato, múltiplos, ligados entre si, a partir de um direcionamento de olhar sobre nossas próprias trajetórias e interesses. Em particular, deseja-se que o estabelecimento de conexões sirva também à construção de identidades, na medida em que favoreçam o desenvolvimento de um sentimento de unidade $\mathrm{e}$ de continuidade entre os países investigados. Assim, a comparação se constituirá em um meio, e não uma finalidade (KRAWCZYK; VIEIRA, 2008).

\section{A educação pública e o ensino de História da América Latina}

Ao longo das últimas duas décadas, Brasil e Argentina, assim com muitos outros países latino-americanos, passaram por uma série de reformas reconhecidas como "neoliberais" no sistema educacional, no intuito paradoxal de universalizar o acesso à educação formal e promover equidade com a redução de gastos públicos (KRAWCZYK; VIEIRA, 2008). Tanto no Brasil como na Argentina, essas reformas foram realizadas em conjunto com o processo de reestruturação democrática após longos períodos de ditadura militar e estão conectadas tanto pela influência de organismos internacionais como pela inspiração em modelos europeus (GVIRTZ; VIDAL; BICCAS, 2009), que atuaram de forma decisiva 
na configuração do atual sistema público de ensino sob respaldo e patrocínio da Organização das Nações Unidas para a Educação, a Ciência e a Cultura (UNESCO), do Programa das Nações Unidas para o Desenvolvimento (PNUD), da Comissão Econômica para a América Latina e o Caribe (CEPAL), do Fundo Monetário Internacional (FMI) e do Banco Interamericano de Desenvolvimento (BID). O resultado foi a implementação de intensos processos de centralização e descentralização administrativa, financeira e curricular, que redistribuiu responsabilidades e ampliou as autonomias institucionais nos diferentes níveis de ensino (KRAWCZYK; VIEIRA, 2008), deixando claro que a busca de soluções para os problemas da educação na América Latina tem muito de construção compartilhada e de procura de referências nos mesmos espaços externos (BRASLAVSKY, 2001, p. 14).

Em ambos os países, essas reformas tiveram como princípio a implementação de novas leis educativas de alcance nacional - na Argentina, com o Presidente Carlos Saúl Menem e a Ministra de Educação Susana Decibe, sancionou-se a "Ley Federal de Educación" (LFE), em 1993; no Brasil, com o Presidente Fernando Henrique Cardoso e o Ministro Paulo Renato de Souza, sancionou-se a "Lei de Diretrizes e Bases da Educação" (LDB), em 1996 (GVIRTZ; VIDAL; BICCAS, 2009). Essas leis constituíram o marco normativo do qual derivaram documentos orientadores da organização curricular de forma centralizada e instrumentalizadora para a nova sociedade que se desejava construir.

Depois de mais de uma década de reformas em atendimento à LFE, as principais normas que regulam o sistema educativo argentino foram novamente modificadas durante o governo do presidente Nestor Kirchner (2003-2007), após um processo de consulta nacional para a elaboração da nova "Ley de Educación Nacional no 26.206" (LEN), sancionada em dezembro de 2006, revogando a LFE (NOSIGLIA, 2007). Em vigor até o momento, a nova LEN foi apresentada como uma alternativa para responder ao descontentamento diante da crise em que entrou o sistema educativo desde o processo de reformas implementado na década de 1990.

A nova lei também avançou na prescrição de conteúdos que deveriam ser incluídos nos desenhos curriculares de cada jurisdição, de onde se destaca:

ARTÍCULO 92. Formarán parte de los contenidos curriculares comunes a todas las jurisdicciones:

a) El fortalecimiento de la perspectiva regional latinoamericana, particularmente de la región del MERCOSUR, en el marco de la construcción de una identidad nacional abierta, respetuosa de la diversidad. (ARGENTINA, CNA, 2006, grifo nosso).

\footnotetext{
${ }^{6}$ Durante todo esse tempo, numerosos projetos de lei de diferentes legisladores, épocas e partidos tentaram realizar modificações parciais e até revogar totalmente a LFE, mas não conseguiram reunir o apoio majoritário necessário para tanto (NOSIGLIA, 2007).
} 
As referências à América Latina também aparecem em outros dois momentos nesta nova lei:

- No artigo 11, referente às finalidades e aos objetivos, consta que um dos objetivos da política educacional do país é "fortalecer la identidad nacional, basada en el respeto a la diversidad cultural y a las particularidades locales, abierta a los valores universales y a la integración regional y latinoamericana” (ARGENTINA, 2006, grifo nosso);

- No artigo 115, referente às atribuições do Ministério da Educação, Ciência e Tecnologia, consta que uma de suas atribuições é "Coordinar y gestionar la cooperación técnica y financiera internacional y promover la integración, particularmente con los países del MERCOSUR” (ARGENTINA, 2006, grifo nosso).

De acordo com a LEN, fica claro que o fortalecimento das perspectivas regionais na América Latina, especialmente em relação ao Mercado Comum do Sul (MERCOSUL), passa pela construção de identidades abertas e respeitosas. Não obstante, o sucesso na integração do país em blocos regionais na América Latina dependerá da forma e da frequência com que esta temática seja incluída não só nas propostas oficiais de ensino, mas também nas práticas escolares cotidianas.

Ao contrário da Argentina, no Brasil segue em vigência a lei implementada no contexto das reformas da década de 1990, com apenas algumas modificações para ajustá-la às novas prerrogativas nacionais e internacionais, sem modificar seu teor. Entre essas modificações se destacam as ocorridas ao longo dos dois mandatos do presidente Luiz Inácio Lula da Silva (2003-2010), como a oferta obrigatória do Espanhol nas escolas de Ensino Médio (2005) e a obrigatoriedade do ensino de História e Cultura Afrobrasileira e Indígena para o Ensino Fundamental e Médio (2008). Mas infelizmente ainda não existe no país uma legitimação normativa específica que indique um direcionamento de olhar para o contexto latino-americano ou para a construção de identidades históricas com os países vizinhos.

De modo comparado, a estrutura do sistema educativo dos dois países possui a seguinte configuração atual: 
Tabela 1 - Idade / Nível de Escolarização, Argentina e Brasil

\begin{tabular}{|c|c|c|c|c|c|c|c|c|c|c|c|c|c|c|c|c|}
\hline Idades & 0 & 12 & 3 & 4 & 6 & 7 & 8 & 9 & 10 & 11 & 12 & 13 & 14 & 15 & 16 & 17 \\
\hline \multirow[b]{2}{*}{ ARGENTINA } & \multicolumn{4}{|c|}{ Nivel Inicial } & \multirow{2}{*}{\multicolumn{6}{|c|}{ Educación Primaria }} & \multicolumn{6}{|c|}{ Educación Secundaria } \\
\hline & \multicolumn{2}{|c|}{$\begin{array}{l}\text { Jardín } \\
\text { Maternal }\end{array}$} & \multicolumn{2}{|c|}{$\begin{array}{c}\text { Jardín } \\
\text { de Infantes }\end{array}$} & & & & & & & \multicolumn{3}{|c|}{ Ciclo Básico } & \multicolumn{3}{|c|}{ Ciclo Orientado } \\
\hline \multirow[b]{2}{*}{ BRASIL } & \multicolumn{4}{|c|}{ Educação Infantil } & \multicolumn{9}{|c|}{ Ensino Fundamental } & \multirow{2}{*}{\multicolumn{3}{|c|}{ Ensino Médio }} \\
\hline & & Creche & & $\begin{array}{l}\text { Pré- } \\
\text { escola }\end{array}$ & & & es in & ciais & & & Série & inais & & & & \\
\hline
\end{tabular}

Fonte: As autoras. Dados obtidos nas legislações atuais dos dois países.

O sistema educativo argentino é o conjunto organizado de serviços e ações educativas reguladas pelo Estado que abarcam os distintos níveis, ciclos e modalidades da educação. Sua organização está a cargo do Ministerio de Educación de la Nación, como instância deliberativa de políticas e estratégias, e do Consejo Federal de Educación, como organismo de concertação e coordenação da política educativa nacional. A administração deste sistema, por sua vez, se encontra de forma descentralizada, sendo que o Estado Nacional, as Províncias e a Ciudad Autónoma de Buenos Aires (CABA) são os responsáveis por planificar, organizar, supervisionar e financiar o sistema educativo, criando e administrando estabelecimentos educativos e estruturando suas próprias matrizes curriculares a partir das diretrizes nacionais ${ }^{7}$.

A estrutura desse sistema compreende quatro níveis: Educación Inicial, Educación Primaria, Educación Secundaria e Educación Superior; e oito modalidades: Educación Técnico Profesional, Educación Artística, Educación Especial, Educación Permanente de Jóvenes y Adultos, Educación Rural, Educación Intercultural Bilingüe, Educación en Contextos de Privación de Libertad e Educación Domiciliaria y Hospitalaria. A frequência é obrigatória desde o último ano do nível Inicial até o final do nível Secundario, em uma trajetória mínima de treze anos.

No Brasil, a organização do sistema educativo está a cargo do Governo Federal, por meio do Ministério da Educação (MEC), que define os princípios orientadores da organização de programas educacionais e do seu financiamento. Os governos locais, em nível estadual e municipal, são responsáveis por estabelecer seus próprios programas educacionais a partir das orientações e diretrizes nacionais, em regime colaborativo de financiamento com a União.

A estrutura do sistema educativo brasileiro está dividida em dois grandes níveis: Educação Básica, composta por Educação Infantil, Ensino Fundamental

\footnotetext{
${ }^{7}$ Desde 1991, o sistema educativo do país está dividido em 24 jurisdições, correspondentes às 23 províncias e à Capital Federal, a cidade de Buenos Aires.
} 
e Ensino Médio, e Educação Superior; e cinco modalidades: Educação Profissional e Tecnológica, Educação de Jovens e Adultos, Educação Especial, Educação Escolar Indígena e Educação a Distância.

De acordo com a legislação vigente, compete aos municípios atuar prioritariamente no Ensino Fundamental e na Educação Infantil, e aos Estados e ao Distrito Federal, no Ensino Fundamental e Ensino Médio. O Governo Federal, por sua vez, exerce, em matéria educacional, função redistributiva e supletiva, cabendo-lhe prestar assistência técnica e financeira aos Estados, ao Distrito Federal e aos Municípios e organizar o sistema de Educação Superior. A frequência é obrigatória em todo o Ensino Fundamental, a partir dos 6 anos de idade, em uma trajetória que equivale a nove anos de escolarização ${ }^{8}$.

O ensino em instituições públicas é gratuito, tanto no Brasil como na Argentina, em todos os níveis e modalidades, sendo também livre à iniciativa privada, e o sistema escolar pode ser organizado com base na idade, em séries anuais, ciclos ou por forma diversa, respeitando-se a legislação local.

$\mathrm{Na}$ Argentina, nos últimos anos do nível Secundario, os alunos devem optar por uma orientação curricular entre distintas áreas do conhecimento, o que definirá seu plano de estudos e sua titulação. No Brasil, a Educação Básica possui uma base comum em todo o país, podendo também diferenciar-se no Ensino Médio com a oferta de modalidades direcionadas à formação técnico-profissional de forma Integrada, que une a formação geral com a formação técnica no mesmo estabelecimento de ensino, ou Concomitante, em instituições de ensino conveniadas, em regime complementar'.

Tanto no Brasil como na Argentina, o ensino superior é oferecido gratuitamente em instituições públicas, e os alunos que tenham concluído a educação escolar, em qualquer modalidade, são considerados habilitados para o ingresso neste nível. No entanto, no Brasil, o acesso ao ensino superior, seja em instituições públicas ou privadas, é condicionado à aprovação em processos seletivos. Já na Argentina, todos os egressos da educação escolar possuem o direito de ingressar em instituições públicas de ensino superior, sem a necessidade de realização de um exame admissional ${ }^{10}$.

\footnotetext{
${ }^{8}$ Desde 2009, com a aprovação da Proposta de Emenda à Constituição (PEC) 96A/03, regulamentou-se também a progressiva obrigatoriedade do Ensino Médio e da Pré-escola no Brasil até o ano de 2016. Dessa forma, o ensino obrigatório no país passará a abranger um período que vai dos 4 aos 17 anos de idade, numa trajetória total de catorze anos de escolarização obrigatória.

${ }^{9}$ Desde 2004, o Ministério da Educação tem apoiado os sistemas estaduais de ensino no processo de implantação da modalidade "integrada" para as instituições públicas de ensino, e atualmente já se conta com a adesão voluntária de mais de vinte Estados da federação.

${ }^{10}$ Em muitos casos, o chamado Ciclo Básico Común, etapa inicial da formação superior em instituições públicas, termina por funcionar como uma espécie de seleção para o ingresso nas carreiras universitárias, devido ao alto nível de exigência dos alunos.
} 
A seleção de professores para o trabalho na educação pública argentina se dá por meio da análise de títulos e de tempo de serviço ${ }^{11}$. A docência na Educación Inicial e na Educación Primaria argentinas é realizada pelos "maestros", que são professores graduados em institutos de educação superior chamados de Escuelas Normales. Na Educación Secundaria e na Educación Superior, a docência é realizada por "profesores", com formação especializada em universidades.

No Brasil, não é muito diferente, a docência na Educação Infantil e nas séries iniciais do Ensino Fundamental $\left(1^{\circ}\right.$ ao $5^{\circ}$ anos) é realizada por professores com graduação em Pedagogia. Já nas séries finais do Ensino Fundamental $\left(6^{\circ}\right.$ ao $9^{\circ}$ anos), no Ensino Médio e no Ensino Superior, a docência é realizada por professores com formação específica nas áreas disciplinares, denominadas "licenciaturas". Mas a seleção de professores para o trabalho tanto na Educação Básica quanto na Educação Superior em instituições públicas do país se dá por meio de concursos públicos ou por processos seletivos simplificados, para suprir necessidades temporárias ${ }^{12}$. Em ambos os casos, é comum a realização de provas de conhecimentos gerais e específicos e a análise de títulos e de tempo de serviço, em caráter classificatório.

O piso salarial dos docentes na Argentina atualmente é de US $\$ 615^{13}$ para uma jornada de trabalho de 20 horas/aula semanais, tanto para a Educación Primaria quanto para a Educación Media, variando entre as diversas jurisdições de acordo com sua arrecadação e com o tempo acumulado de serviço no magistério. Já no Brasil, o piso salarial nacional para os profissionais da Educação Básica atualmente é de US $\$ 735$ para uma jornada de trabalho de 40 horas/aula semanais - quase a metade do que se paga na Argentina -, também variando de acordo

\footnotetext{
${ }^{11}$ Geralmente, ao término de um curso de formação docente, também conhecido como "Profesorado", o profissional interessado pode se inscrever para dar aulas em uma ou várias modalidades do ensino público, apresentando seu currículo e os certificados de sua formação. Este currículo é avaliado por uma junta classificatória, e, a partir da pontuação obtida, os professores são contratados como "interinos", assumindo uma vaga em determinada escola, ou como "suplentes", cobrindo períodos de licença de outros professores. Com o passar do tempo, esses professores podem chegar a ser "titulares" da vaga ocupada se atenderem aos critérios estabelecidos pelos programas de progressão de carreira.

${ }^{12}$ Em muitos Estados e Municípios do país, a contratação de "professores temporários" tem sido realizada sucessivamente para reduzir gastos públicos, o que compromete a qualidade de ensino, devido à rotatividade dos professores. Em geral, os contratos são realizados para o prazo determinado de um ano letivo, e, ao final deste período, os professores são dispensados para serem novamente contratados no início do ano seguinte, após novo processo seletivo e sem a garantia de permanecer na mesma escola. Trata-se de uma questão econômica: é muito mais barato para a administração pública contratar um professor por um prazo determinado do que manter regularmente um professor efetivo no exercício de sua função.

${ }^{13}$ Os valores apresentados foram divulgados pelos respectivos governos nacionais no início de 2013 para garantir um piso salarial mínimo ao longo de todo o ano. A conversão foi feita para o dólar para efeito de comparação, utilizando a cotação estabelecida nos dois países em 6 de junho de 2013.
} 
com a arrecadação estadual/municipal ${ }^{14}$. Em ambos os países, a precariedade salarial associa-se à precarização das condições de trabalho pedagógico, entre outros fatores, pelo grande número de alunos por professor, em todos os níveis de escolarização, e pelo aumento das enfermidades laborais, tornando cada vez menor a procura pela profissão.

As propostas curriculares dos dois países, das quais trataremos mais adiante, devem seguir a base nacional comum, a ser complementada, em cada sistema de ensino e estabelecimento escolar, por uma parte diversificada, exigida pelas características locais de sua área de atuação. No Brasil, esta base comum foi regulamentada pelos Parâmetros Curriculares Nacionais (PCN), implementados a partir de 1997 em atendimento à nova LDB. Em geral, no país, a grade de disciplinas na Educação Básica está dividida em um núcleo comum (Português, História, Geografia, Matemática, Ciências, Educação Física e Educação Artística) e um núcleo diversificado, que inclui uma segunda língua moderna e outras disciplinas. A disciplina de História está estabelecida como espaço curricular autônomo a partir das séries finais do Ensino Fundamental ( $6^{\circ}$ ao $9^{\circ}$ anos) e ao longo de todo o Ensino Médio, variando sua carga horária de acordo com a modalidade "Regular" ou "Profissional" e com as regulamentações estaduais e municipais. Em geral, no Ensino Fundamental Regular, a disciplina conta com duas horas/aula semanais nas séries iniciais do Ensino Fundamental $\left(1^{\circ}\right.$ ao $5^{\circ}$ anos) e três horas/aula nas séries finais $\left(6^{\circ}\right.$ ao $9^{\circ}$ anos) e ao longo do Ensino Médio, podendo variar de acordo com o Estado, o Município ou a escola.

$\mathrm{Na}$ Argentina, por sua vez, a base nacional comum para as propostas curriculares estão estabelecidas nos Contenidos Básicos Comunes (CBC), implementados a partir de 1995, juntamente com a LFE, e nos Núcleos de Aprendizaje Prioritario (NAP), implementados a partir de 2004, no contexto de recentralização educativa do governo de Nestor Kirchner, que antecedeu a LEN. Nesses documentos, a disciplina de História não aparece como espaço curricular autônomo, mas em conjunto com outros campos do conhecimento como Geografia, Sociologia, Economia, Antropologia e Ciência Política, em uma área disciplinar chamada de Ciencias Sociales. No entanto, esta divisão por área não chegou a afetar a organização tradicional das disciplinas nas escolas. Nas escolas argentinas, a grade de disciplinas também pode variar em cada jurisdição educativa, mas é comum a consideração de uma base geral, composta por Matemática, Biología, Físico-Química, Lengua, Geografía, Historia, Educación Cívica, Idioma Extranjero, Educación Artística e Educación Física. A disciplina de História está estabelecida a partir da Educación Secundaria, com uma carga

\footnotetext{
${ }^{14}$ De acordo com a Confederação Nacional dos Trabalhadores em Educação (CNTE), do Brasil, menos da metade dos Estados e Municípios do país garante o pagamento do valor mínimo estabelecido pelo piso nacional.
} 
horária semanal que varia entre uma a quatro horas/aula, dependendo da orientação escolhida.

A análise comparada dos sistemas educativos dos dois países aponta para uma crescente padronização dos currículos escolares oficiais, sublinhando o papel do Estado na organização dos conhecimentos socialmente desejados. Ainda que os dois países variem consideravelmente nos problemas, temas e práticas pedagógicas, as categorias e os meios básicos com que organizam os conhecimentos na escola estão padronizados, assim como a definição oficial das disciplinas e a carga horária dedicada a cada uma delas.

No nível primário, a maior parte dos conhecimentos escolares é definida em seis áreas temáticas: língua, matemática, ciências naturais, ciências sociais, educação artística e educação física. Nesse conjunto, a ênfase está no aprendizado da língua e de matemática. A inclusão de outras matérias depende das condições históricas e culturais de cada região. No nível secundário, por sua vez, parece delinear-se um modelo geral bem estabelecido de organização, composto primeiramente por um programa escolar global, que inclui um número de matérias padronizadas, seguido por um direcionamento a programas de estudo especializados, escolhidos pelos alunos, com orientação profissional.

A história da América Latina, por sua vez, aparece diluída entre a história nacional e mundial tanto no Brasil como na Argentina, e seu ensino está submetido às opções, políticas em primeira instância, dos docentes envolvidos no processo de aprendizagem. Embora a temática possa ser encontrada nas diretrizes curriculares oficiais e nos livros didáticos, é recorrente a constatação de que pouco se estuda sobre o continente em ambos os países, em função de um privilégio muito grande da história europeia e nacional, o que resulta numa forma de isolamento. Além disso, a fragmentação dos conteúdos e a forma como essas temáticas são trabalhadas separadamente do estudo do contexto nacional dificultam a aproximação com os países vizinhos.

Por outro lado, observa-se grande incremento da temática no ensino de conhecimentos ligados a Geografia, o que traz à tona o debate recorrente sobre o entendimento do continente apenas como um território, um lugar, em detrimento da ideia de que o que faz a região não é o espaço, e sim o tempo, a história (BORIS, 1960 apud BOURDIEU, 1989).

Já na década de 1980, Hilda Lanza e Silvia Finocchio investigavam a presença da temática latino-americana nos currículos e materiais didáticos mais difundidos da Argentina e apontavam a maneira escassa e fragmentária de seu tratamento: 
En la Argentina, aparentemente, el proceso de transmisión de contenidos propuestos desde los sectores hegemónicos que aseguraran la lealtad al Estado Nacional, fue simultáneo a la transmisión de una imagen deteriorada de la historia de América Latina y revalorizada respecto del mundo europeo. (LANZA; FINOCCHIO, 1993, p. 19).

De acordo com as autoras, nas reformas educacionais propostas para o nível médio ao longo da maior parte do século XX, os conteúdos referentes ao ensino de História da América Latina sofreram um processo de esquecimento, desconsideração e empobrecimento, especialmente no que se refere a aspectos sociais e econômicos. Algumas das razões deste processo estão relacionadas à frequente ruptura da ordem institucional, assim como sua incidência em políticas educativas e na renovação continuada de alternativas historiográficas. Os livros didáticos produzidos a partir dessas propostas também seguiram tal tendência, mantendo a baixa qualidade das propostas oficiais e ainda agregando uma série de valores subjetivos apresentados como verdades científicas em um discurso unilateral (LANZA; FINOCCHIO, 1993, p. 34 e p. 80).

Com a implementação de novas reformas nas duas últimas décadas, a situação não se alterou muito, pois, mesmo que a elaboração de novas matrizes curriculares tenha encaminhado os primeiros passos para o entendimento de uma história mais integrada, a seleção e a organização dos conteúdos a serem ensinados dependem em grande parte das opções particulares, políticas e didáticas, dos docentes envolvidos no processo.

No Brasil, por sua vez, novas perspectivas foram introduzidas no ensino da História da América Latina com os Parâmetros Curriculares Nacionais de História. Da mesma forma, é possível observar que muitas coleções de livros didáticos têm incluído algumas propostas de trabalho com a temática. No entanto, a fragmentação dos conteúdos e a forma como muitas vezes essas temáticas são trabalhadas, quando chegam a ser trabalhadas, não favorecem a aproximação com os países vizinhos, pela exotização do "outro" latino-americano, em detrimento de uma visão integrada da história do continente, em que prevaleçam as similitudes do seu processo histórico (CONCEIÇÃ̃, 2010).

Em um estudo sobre a presença da temática nos programas e manuais escolares brasileiros do século XIX ao XXI, Circe Bittencourt (2005) comenta que conteúdos escolares de História da América podem ser encontrados em vários momentos da trajetória escolar brasileira, mas quem determina seu ensino é o professor, na constituição da disciplina e na seleção dos conteúdos significativos, o que remete diretamente às formas de apropriação de tais documentos.

Em relação à presença da temática nos conteúdos escolares relacionados ao ensino de Geografia, Wagner da Silva Dias (2011) comenta a presença da ideia de uma homogeneidade estereotipada do continente no ensino da disciplina: 
Parece-nos que há um esforço para entender que a América Latina surgiu assim que os europeus ocuparam o continente, instalaram suas colônias de exploração e, mesmo após os processos de independência política, permaneceram subjugando econômica e politicamente os países da região. Também há pouca reflexão para a ideia de que "se somos pobres é porque nos exploram", uma vez que a participação das elites locais é suprimida, ou então querem nos fazer crer que e exploração se deu unicamente pelo uso da força sem que nenhum grupo social interno aos países houvesse se beneficiado ao longo da história. (DIAS, 2011, p. 5).

Ainda que as discussões sobre a construção de identidades integradoras no continente remontem ao século XIX e que a temática esteja presente nos programas de ensino e manuais escolares de maneira recorrente em vários países ao longo do século XX, tornando-se inclusive objeto de vários estudos sobre seu ensino nas disciplinas escolares, a superação do desconhecimento dos países entre si permanece um desafio e tem levado a distorções nas histórias nacionais e à produção de preconceitos e estereótipos.

Um dado que chama atenção nos países investigados é que tem aumentado o número de denúncias de discriminação em estabelecimentos escolares contra alunos provenientes de outros países latino-americanos, que em geral estão em condições sociais e econômicas desfavorecidas nos dois países. Em muitos casos, essas posturas discriminatórias traduzem-se em atitudes xenofóbicas, expressas tanto nas formas simbólicas de segregação do espaço escolar quanto na agressão verbal e física. Essas posturas têm se consolidado nas últimas décadas com o aumento do número de imigrantes de países limítrofes na Argentina e no Brasil e colocam em evidência os desafios a serem enfrentados na construção de perspectivas integradas não só da história, mas também das pessoas no continente.

A partir disso, as questões que se colocam são: podem os conteúdos curriculares isolados das mudanças que ocorrem paralelamente nas famílias e comunidades gerar e sustentar nos jovens atitudes de empatia, tolerância e respeito em relação ao "outro"? Podemos esperar que os programas escolares facilitem o entendimento mútuo entre comunidades e países? (BENAVOT, 2002, p. 67). A contribuição precisa da escolarização na construção de memórias e identidades orientadas à diversidade cultural que nos habita permanecerá ambígua até que se avalie em que medida os jovens adquirem tais perspectivas na escola ou fora dela. 


\section{A história da América Latina nas diretrizes curriculares nacionais}

As transformações curriculares ocuparam um lugar de destaque nas reformas educacionais das últimas décadas tanto no Brasil como na Argentina, no intuito de renovar e atualizar disciplinas e conteúdos para o atendimento às novas leis nacionais, implementadas a partir da década de 1990.

Ivor Goodson (2007, p. 242) lembra que os currículos oficiais, enquanto prescrições, sustentam místicas importantes sobre o papel do Estado, da escolarização e da sociedade na aprendizagem "primária", a partir da crença de que é possível definir imparcialmente os principais ingredientes do desenvolvimento do estudo e, então, ensinar os vários segmentos e sequências de uma forma sistemática. Mais especificamente, ele sustenta a mística de que a especialização e o controle são inerentes ao governo central, às burocracias educacionais e à comunidade universitária. Ainda que isso não seja comprovado na "escolarização como prática", a utilização de currículos oficiais como fontes de pesquisa permite observar a interseção do político com o cultural, pois são instrumentos privilegiados de comunicação da história a ser ensinada e de elaboração e divulgação de memórias e identidades, refletindo traços importantes da sociedade que o produz, da cultura que circula ao seu entorno e da que regula suas práticas de uso.

Tanto no Brasil quanto na Argentina, as diretrizes curriculares nacionais ${ }^{15}$ deveriam garantir um sistema educativo integrado e, ao mesmo tempo, flexível, de maneira que permitisse a incorporação de elementos das características locais em cada área de atuação. Nessa perspectiva, elas deveriam ser complementadas por diretrizes estaduais, jurisdicionais e municipais, assim como pelas orientações de cada escola. Desse modo, as prescrições curriculares determinam alguns parâmetros, mas algumas transgressões ou transcendências ocasionais são permitidas, desde que a retórica e o gerenciamento das prescrições não sejam desafiados (GOODSON, 2007, p. 242).

Nas diretrizes curriculares nacionais argentinas, tanto para a Educación Primaria como para a Secundaria, a disciplina de História não aparece como espaço curricular autônomo, mas em conjunto com outros campos do conhecimento, cujo objetivo principal seria a formação de uma "competencia

\footnotetext{
${ }^{15}$ Para este artigo, foram analisadas as seguintes diretrizes curriculares nacionais do Brasil e da Argentina:

- Brasil: Parâmetros Curriculares Nacionais de História para o Ensino Fundamental e Médio e PCN+ Ensino Médio - Ciências Humanas e suas Tecnologias.

- Argentina: Contenidos Básicos Comunes de Ciencias Sociales para a Educación General Básica, Contenidos Básicos para a Educación Polimodal - Humanidades y Ciencias Sociales, Marcos de Referencia de Educación Secundaria Orientada - Bachiller en Ciencias Sociales e Núcleos de Aprendizajes Prioritarios para a Educación General Básica.

A lista completa dos documentos analisados encontra-se nas referências bibliográficas.
} 
sociocomunitaria". No Brasil, ao contrário, a nova apresentação por área dos PCN reconheceu a autonomia da disciplina, inclusive para os primeiros níveis de ensino, após longos períodos de "Estudos Sociais" (BRASIL, 1997, p. 22). Já no que se refere ao ensino de conhecimentos históricos da América Latina, nenhuma das duas propostas deu grande destaque à temática, priorizando o ensino de conteúdos da própria história nacional e da história europeia.

Nas propostas curriculares nacionais da Argentina, a referência direta ao estudo da história da América Latina aparece com mais evidência para a Educación Primaria, compreendendo um período que vai desde o estudo das civilizações indígenas da América na antiguidade ${ }^{16}$ até a situação atual do continente no mundo contemporâneo. Ao longo desta etapa, a prioridade está no estudo das conexões entre a história latino-americana e a europeia, especialmente no que se refere ao sistema colonial hispano-americano e às lutas de independência. Já no nível Secundario, a ênfase está no estudo de temáticas mais contemporâneas, como o populismo, o desenvolvimentismo, os governos autoritários e a reconstrução da democracia, passando pelos ciclos econômicos até as reformas dos anos 1990. Desse modo, parece delinear-se uma sequência temporal, fazendo que as discussões mais atuais estejam presentes apenas nos últimos anos de formação. Nessas propostas, a América Latina parece ser destacada menos como conteúdo e mais como escala de análise, como um meio-termo entre o local e o mundial, o que, em parte, revela a identificação de aproximações com a história dos vários países da região, que partilham trajetórias históricas próprias.

No Brasil, as referências diretas ao ensino de conhecimentos históricos da América Latina podem ser encontradas apenas nas propostas curriculares para as séries finais do Ensino Fundamental, com especial destaque para os conflitos, as guerras e as revoluções, que caracterizam não só a história do continente, mas também as relações entre os países que o compõem. Nessa medida, aponta-se tanto para a importância da formação de blocos regionais quanto para o intervencionismo norte-americano na América Latina. No entanto, a forma como essas temáticas são apresentadas separadamente do estudo da história brasileira não favorece a construção de aproximações do país com os países vizinhos. Nas propostas para o Ensino Médio, os documentos curriculares nacionais brasileiros não fazem referência direta à temática latino-americana, o que revela o desinteresse pela construção de identidades históricas com os demais países do continente.

A análise comparada das diretrizes curriculares nacionais dos dois países revela que as referências ao ensino de História da América Latina permanecem

\footnotetext{
${ }^{16}$ Ainda que o termo "América Latina” tenha sido cunhado apenas no século XIX, levou-se em consideração a presença de conteúdos referentes à história do continente anteriores a este período pelas possibilidades de construção de identidades históricas entre os países da região a partir da identificação de um passado comum.
} 
fragmentadas, destacando-se com clareza apenas na indicação de conteúdos relacionados ao período colonial e à formação dos Estados nacionais, com as lutas por independência. Isso implica que as possibilidades de construção de identidades históricas com os demais países do continente se referem apenas a um passado longínquo, em que o próprio termo foi formado. No entanto, em nenhum dos documentos analisados, ao se tratar da temática latino-americana, seja como conteúdo ou como escala de análise, comenta-se a definição de América Latina utilizada, nem se alude à história do termo ou às identidades que ele enseja. Além disso, essas temáticas aparecem com mais frequência apenas nos currículos que abrangem a faixa etária dos 11 aos 14 anos, sem que haja uma continuidade nos estudos das séries seguintes, quando a capacidade dos alunos de estabelecer um olhar mais crítico sobre o presente está mais aguçada, assim como seu potencial de engajamento político.

A partir daí, é possível concluir que, embora a temática tenha ganhado certo destaque na atual legislação educativa argentina, a construção de identidades históricas com os demais países do continente, via ensino de História, permanece um desafio em ambos os países. Ainda que as diretrizes curriculares sinalizem para a importância da temática, a seleção e a organização dos conteúdos indicados para normatizar o ensino nacional não permitem qualquer reflexão mais atual, nem a superação do desconhecimento dos países entre si, o que resulta numa forma de isolamento e reflete os compromissos nacionalistas na construção de identidades, via ensino de História. Além disso, a predominância de conteúdos relacionados à Europa evidencia que seguimos buscando referências externas para tratarmos de nosso próprio passado e, consequentemente, nosso futuro.

Ainda que os planos e programas de estudo sejam definidos, na prática, pelos professores de cada escola, a partir de suas opções políticas e também pedagógicas (VENERA; CONCEIÇÃO, 2012), a falta de clareza com que a temática aparece nas propostas oficiais implica uma grande dificuldade no direcionamento de olhar para os laços que unem cada história nacional, limitando as construções identitárias a vieses nacionalistas. Isso porque, em grande medida, os cursos de formação de professores e as avaliações externas da educação são projetados para contemplar essas propostas, criando limites a sua transcendência. Somado a isso, acrescentam-se as péssimas condições de trabalho e os baixos salários dos profissionais do ensino público em ambos os países, que comprometem as possibilidades de criação e inovação sobre as propostas curriculares oficiais. 


\section{Considerações finais}

A realização de pesquisas em documentos oficiais de amplitude nacional em países tão complexos como Brasil e Argentina certamente impõe limites ao entendimento de aspectos práticos do sistema educacional. Por isso, ressalta-se a importância de pesquisas direcionadas à história efetivamente ensinada e apreendida nas salas de aula ${ }^{17}$ para se compreender, de fato, a quais processos formativos os jovens latino-americanos estão submetidos na atualidade, quais saberes históricos são privilegiados e quais recursos são mobilizados nesta formação. Ainda assim, a utilização de documentos oficiais como fontes históricas e educacionais permite observar os processos de enquadramento de memórias públicas, na interseção do político com o cultural. São, portanto, instrumentos privilegiados na investigação da educação como estratégia política de difusão e consolidação de representações e identidades, à medida que muda, na sociedade, a função da História.

\section{Referências}

ARDAO, A. Génesis de la idea y el nombre de América Latina. Caracas: Centro de Estudios latinoamericanos Rómulo Gallegos/V Consejo Nacional de la Cultura, 1980.

ARGENTINA. Congreso de la Nación Argentina. Ley $\mathbf{n}^{\circ}$ 26.206, de 14 de dezembro de 2006. Ley de Educación Nacional. Buenos Aires, 2006.

ARGENTINA. Consejo Federal de Educación. Marcos de Referencia Educación Secundaria Orientada. Bachiller en Ciencias Sociales. Buenos Aires: Consejo Federal de Educación, 2011.

ARGENTINA. Ministerio de Cultura y Educación. Consejo Federal de Cultura y Educación. Contenidos básicos para la educación polimodal. Humanidades y Ciencias Sociales. Buenos Aires: Ministerio de Cultura y Educación de la Nación, 1997.

ARGENTINA. Ministerio de Cultura y Educación. Consejo Federal de Cultura y Educación. Contenidos básicos comunes para la educación general básica. Buenos Aires: Ministerio de Cultura y Educación de la Nación, 1995.

ARGENTINA. Ministerio de Educación, Ciencia y Tecnología. Núcleos de Aprendizajes Prioritarios. Nivel Primario. Buenos Aires: Ministerio de Educación, Ciencia y Tecnología, 2004.

ARGENTINA. Ministerio de Educación, Ciencia y Tecnología. Núcleos de Aprendizajes Prioritarios. Nivel Medio. Buenos Aires: Ministerio de Educación, Ciencia y Tecnología, 2005.

\footnotetext{
${ }^{17} \mathrm{O}$ artigo "Tensões curriculares e narrativas: o ensino de História da América Latina", de Raquel Alvarenga Sena Venera e Juliana Pirola da Conceição (2012), traz algumas reflexões sobre as práticas curriculares desenvolvidas para o ensino de História da América Latina em sua relação com a produção de narrativas históricas por jovens estudantes do ensino público da cidade de Florianópolis, Santa Catarina.
} 
BENAVOT, A. A educação para aprender a viver juntos: uma análise crítica da pesquisa comparada. In: BRASLAVSKY, C. (Org.). Aprender a viver juntos: educação para integração na diversidade. Brasília: UNESCO, IBE, SESI, UnB, 2002. p. 65-92.

BITTENCOURT, C. M. F. Ensino de História da América: reflexões sobre problemas de identidades. Revista Eletrônica da ANPHLAC, São Paulo, n. 4, p. 5-15, 2005.

BOURDIEU, P. A identidade e a representação: elementos para uma reflexão crítica sobre a ideia de região. In: BOURDIEU, P. O poder simbólico. Lisboa: Difel, 1989. p. 107-132.

BRASIL. Ministério da Educação. Lei $\mathbf{n}^{\circ}$ 9.394, de 20 de dezembro de 1996. Leis de Diretrizes e Bases da Educação Brasileira, Brasília, 1996.

BRASIL. Secretaria da Educação Média e Tecnológica. PCN+ Ensino Médio: Orientações Educacionais complementares aos Parâmetros Curriculares Nacionais. Ciências Humanas e suas Tecnologias. Brasília: MEC, 2002.

BRASIL. Secretaria de Educação Fundamental. Parâmetros Curriculares Nacionais: História, Geografia (1 e $2^{\circ}$ ciclos do Ensino Fundamental). Brasília: MEC/SEF, 1997.

BRASIL. Secretaria de Educação Fundamental. Parâmetros Curriculares Nacionais: História (3º e $4^{\circ}$ ciclos do Ensino Fundamental). Brasília: MEC/SEF, 1998.

BRASIL. Secretaria de Educação Média e Tecnológica. Parâmetros Curriculares Nacionais (Ensino Médio): Ciências Humanas e suas Tecnologias. Brasília: MEC, 2000.

BRASLAVSKY, C. As novas tendências mundiais e as mudanças curriculares na educação secundária latino-americana na década de 90. 2. ed. Brasília: UNESCO, 2001.

BRUIT, H. A invenção da América Latina. In: ENCONTRO DA ANPHLAC, 5., 2000, Belo Horizonte. Anais... Belo Horizonte: ANPHLAC, 2000.

CARDOSO, F. H. Desenvolvimento e identidade latino-americana. Nossa América, Revista Memorial da América Latina, n. 23, ano 2006. Disponível em: <www.memorial.sp.gov.br/ revistaNossaAmerica/23/port/ 55-debate.htm>. Acesso em: 20 mar. 2007.

CONCEIÇÃO, J. P. da. Ensino de História e consciência histórica latino-americana no Colégio de Aplicação da UFSC. 2010. 171 f. Dissertação (Mestrado em Educação) Universidade Federal de Santa Catarina, Florianópolis, 2010.

CONCEIÇÃO, J. P. da; DIAS, M. de F. S. Ensino de História e consciência histórica latinoamericana. Revista Brasileira de História, São Paulo, v. 31, n. 62, p. 173-191, dez. 2011.

CONCEIÇÃO, J. P da.; ZAMBONI, E. Ensino de história e identidade latino-americana: essência a buscar ou projeto a construir? In: ENCONTRO NACIONAL PERSPECTIVAS DO ENSINO DE HISTÓRIA, 8., 2012, Campinas. Anais... Campinas, 2012.

CUESTA FERNANDEZ, R. Sociogénesis de una disciplina escolar: la Historia. Barcelona: Pomares-Corredor, 1997.

DESCHAMPS, J. C.; MOLINER, P. A identidade em psicologia social: dos processos identitários às representações sociais. Petrópolis: Vozes, 2009.

DIAS, W. S da. Qual América Latina? Os livros didáticos e suas referências teóricas para a construção da região. Revista Geográfica de América Central, Costa Rica, v. 2, n. 47, Especial, pp. 1-13, 2011. 
FARRET, R. L.; PINTO, S. R. América Latina: da construção do nome à consolidação da ideia. Topoi, Rio de Janeiro, v. 12, n. 23, p. 30-42, jul./dez. 2011.

FRANCO, M. C. Quando nós somos o outro: questões teórico-metodológicas sobre os estudos comparados. Educação \& Sociedade, Campinas, v. 21, n. 72, p. 197-230, ago. 2000.

GOODSON, I. Currículo, narrativa e o futuro social. Revista Brasileira de Educação, Rio de Janeiro, v. 12, n. 35, p. 241-252, maio/ago. 2007.

GRUZINSKI, S. O historiador, o macaco e a centaura: a "história cultural" no novo milênio. Revista Estudos Avançados, São Paulo, v. 17, n. 49, p. 321-342, set./dez. 2003.

GVIRTZ, S.; VIDAL, D.; BICCAS, M. As reformas educativas como objeto de pesquisa em História Comparada da Educação na Argentina e Brasil. In: VIDAL, D. G.; ASCOLANI, A. (Org.). Reformas educativas no Brasil e na Argentina: ensaios de História Comparada da Educação (1820-2000). São Paulo: Cortez, 2009. p. 13-42.

KRAWCZYK, N. R.; VIEIRA, V. L. A reforma educacional na América Latina nos anos 1990: uma perspectiva histórico-sociológica. São Paulo: Xamã, 2008.

LANZA, H.; FINOCCHIO, S. Currículum presente, ciencia ausente: la enseñanza de la historia en la Argentina de hoy. Buenos Aires: FLACSO. Programa Argentina, CIID, Miño y Dávila, 1993.

LEITE, J. L. Ensino de História e história do Espírito Santo. Módulo História 3 da disciplina Estudos Sociais do curso de Pedagogia à distância. Vitória: NEAD/UFES, 2004.

MIGNOLO, W. La idea de América Latina: la herida colonial y la opción decolonial. Barcelona: Gedisa, 2005.

NOSIGLIA, M. C. El proceso de sanción y el contenido de la Ley de Educación nacional n ${ }^{\circ}$ 26.206: continuidades y rupturas. Revista Práxis Educativa, Santa Rosa, n. 11, p. 113-138, mar. 2007.

POLLAK, M. Memória, esquecimento, silêncio. Revista Estudos Históricos, Rio de Janeiro. v. 2, n. 3, p. 3-15, 1989.

POLLAK, M. Memória e identidade social. Revista Estudos Históricos, Rio de Janeiro, v. 5, n. 10, p. 200-212, 1992.

PRADO, M. L. C. Repensando a história comparada da América Latina. Revista de História, São Paulo, n. 153, p. 11-33, dez. 2005.

QUIJADA, M. Sobre el origen y difusión del nombre "América Latina" (o una variación heterodoxa en torno al tema de la construcción social de la verdad). Revista de Índias, Madrid, v. LVIII, n. 214, p. 595-615, 1998.

REICHEL, H. J. A identidade latino-americana na visão dos intelectuais da década de 1960. Estudos Ibero-Americanos, Porto Alegre, v. XXXIII, n. 2, p. 116-133, dez. 2007.

ROJAS MIX, M. Los cien nombres de América. Barcelona: Editorial Lumen, 1991.

SADER, E. Introdução. In: SADER, E.; JINKINGS, I.; MARTINS, C. E.; NOBILE, R. (Coords.). Latinoamericana: enciclopédia contemporânea da América Latina e do Caribe. São Paulo: Boitempo, 2006. p. 29-32. 
SUBRAHMANYAM, S. Connected Histories: Notes towards a Reconfiguration of Early Modern Eurásia. Modern Asian Studies, v. 31, n. 3, Special Issue: The Eurasian Context the Early Modern History of Mainland South East Asia, 1400-1800, p. 735-762, jul. 1997.

VENERA, R. A. S.; CONCEIÇÃO, J. P. Tensões curriculares e narrativas: o ensino de História da América Latina. Revista Tempo e Argumento, Florianópolis, v. 4, n. 2, p. 128 151, jul./dez. 2012.

VIDAL, D. G. História da educação comparada: reflexões iniciais e relato de uma experiência. Revista História da Educação, Pelotas, v. 5, n. 10, p. 31-41, out. 2001.

VIDAL, D. G.; ASCOLANI, A. (Org.). Reformas educativas no Brasil e na Argentina: ensaios de história comparada da educação (1820-2000). São Paulo: Cortez, 2009.

ZAMBONI, E. Projeto pedagógico dos parâmetros curriculares nacionais: identidade nacional e consciência histórica. Cadernos CEDES, Campinas, v. 23, n. 61, p. 367-377, dez. 2003.

Recebido em 20/02/2013

Versão final recebida em 10/06/2013

Aceito em 17/06/2013 